\title{
UPOTREBA DRUŠTVENIH MREŽA U HIBRIDNOM RATOVANJU
}

\author{
Radiša Saković \\ Sektor za politiku odbrane, Uprava za strategijsko planiranje \\ Miroslav R. Terzić \\ Univerzitet odbrane u Beogradu, Škola nacionalne odbrane
}

Eenomen društvenih mreža počeo je da se razvija krajem prošlog i početkom ovog veka, a od 2004. godine njegov razvoj poprima eksponencijalni karakter. Razvoj društvenih mreža, pored povezivanja ljudi, stvorio je prostor za delovanje u različitim segmentima društva (ekonomija, kultura, sport, odbrana i bezbednost, politika i slično) tako da su glavne aktivnosti koje kontrolišu ljudski život međusobno povezane.

Neka delovanja u različitim segmentima društva, pomoću društvenih mreža, mogu imati hibridni karakter i predstavljati pretnju po nacionalnu bezbednost. Takođe, društvene mreže je moguće iskoristiti za suzbijanje i suprotstavljanje hibridnim pretnjama. Delovanje na društvenim mrežama se, najčešće, povezuje sa primenom meke moći u hibridnom ratovanju zato što obuhvata nekonvencionalni deo sukoba. Mogućnost iskorišćenja društvenih mreža u hibridnom ratovanju je veoma velika i može obuhvatati poziv građanima na bojkot, okupljanja i neposlušnost, regrutovanje i obuku stanovništva za suprotstavljanje pojedinim pretnjama, (dez)informisanje, kreiranje javnog mnjenja i slično.

Zbog toga su autori u ovom radu analizirali najpopularnije društvene mreže, hibridne pretnje i prikazali upotrebu društvenih mreža u pojedinim sukobima koji su imali karakter hibridnog rata.

Ključne reči: društvene mreže, hibridne pretnje, hibridno ratovanje, sukob

Složenost bezbednosnog okruženja moguće je razumeti analizom više dimenzionalnog

sukoba na nacionalnom, regionalnom i globalnom nivou između državnih i nedržavnih subjekata ili između različitih interesnih grupa radi ostvarivanja određenih ciljeva, koji su najčešće političke prirode. Ovakve težnje strana u sukobu nekada je moguće ostvariti samo primenom tvrde ili meke moći, a nekada i njihovom kombinacijom. Ove specifičnosti ukazuju na revidiranje ili promene paradigme ratovanja uzimajući u obzir nove strategije, specifične taktike, metode i postupke, kako na lokalnom i regionalnom, tako i na globalnom (svetskom) nivou.

U većini globalnih bezbednosnih strategija, analizirajući savremeno geopolitičko okruženje, u kontekstu bezbednosti i odbrane sve više se pominju društvene mreže i hibridne pretnje, dovodeći se u česte uzročno-posledične veze i odnose. Ovakve korelacije, 
dovele su do saznanja koja imaju niz pozitivnih dostignuća za ljudsko društvo, ali su proizvele i veliki broj negativnih implikacija po bezbednost i slobodu čoveka.

Društvene mreže su nastale, najpre, kao posledica potrebe da se ljudi sa sličnim interesovanjima povežu i razmenjuju iskustva, a vremenom su postale mesta na kojima ljudi dele informacije o važnim događajima iz svog života, interesovanjima, sportu koji preferiraju, mestima koja posećuju, muzici koju slušaju, zanimljivostima iz ličnog okruženja i slično. S obzirom na raznovrsnost i veliku količinu informacija koje su dostupne preko društvenih mreža, one se mogu iskoristiti i kao alat za manipulaciju (širenje dezinformacija, komentarisanje aktuelnih događaja, poziv na različita okupljanja i dr.) ciljnom grupom koja može obuhvatati stanovništvo određenog regiona, odnosno populaciju svih uzrasta u različitim oblicima društvene delatnosti i tako ostvariti psihološko-propagandni uticaj na svest ljudi.

Među najpopularnijim društvenim mrežama ističu se: Facebook, Qzone, Google+, Twitter, Linkedln, Instagram, Skype i WhatsApp. Pored navedenih, postoje i mnoge druge manje poznate društvene mreže, koje se koriste na regionalnom, pa čak i nacionalnom nivou, kao što su: VK (Rusija, Ukrajina, Belorusija, Kazahstan i Uzbekistan), Odnoklassniki (Rusija), QZone (Kina), Weibo (Kina), Renren (Kina), Taringa! (Argentina, Urugvaj, Paragvaj, Čile), Mixi (Japan), Xing (Nemačka, Austrija, Švajcarska), Facenama (Iran, Irak), Cloob (Iran, UAE), Draugiem (Letonija, Litvanija, Estonija) itd.

Pojedini teoretičari, među kojima prednjači Frenk Hofman ${ }^{1}$, pominju hibridno ratovanje u kontekstu novih formi sukoba. Do sada nije zvanično određen pojam, niti je postavljena definicija hibridnog ratovanja, ${ }^{2}$ mada se vodila naučna i stručna rasprava o hibridnom ratovanju. Sinhronizovana primena savremenih (ne)borbenih metoda i tehnika u sukobima nametnula je potrebu za traženjem odgovarajućeg pojma (termina) koji će ih objediniti u jednu celinu i nazvati jedinstvenim imenom. Zbog navedenog terminološkog traganja (lutanja), sve češće su u upotrebi termini: hibridno ratovanje, hibridni sukob, hibridne pretnje i slično.

Međutim, evolucija sukoba ostvaruje određeni uticaj na strane u sukobu da primenjuju raznovrsne metode i tehnike radi dostizanja željenog krajnjeg stanja, pri čemu u sferi informacionog ratovanja upotreba društvenih mreža zauzima sve značajnije mesto. Ovakav trend nastupio je u prethodnih desetak godina, kada su ljudi postali (ne)svesni snage (moći) koju pruža mogućnost njihovog informacionog povezivanja. U tom kontekstu, na početku 21. veka, sa novim izazovima po nacionalnu, regionalnu i međunarodnu bezbednost teži se pojmovnom određenju i konceptualizaciji, ne samo hibridnih pretnji i hibridnog ratovanja, već i novih formi informacionog ratovanja, gde je nemoguće zaobići društvene mreže.

\footnotetext{
${ }^{1}$ Frenk Hofman je bivši pripadnik Ratne mornarice OS SAD do juna 2011. U junu 2011. postaje direktor Univerziteta nacionalne odbrane SAD.

${ }^{2}$ Pojam hibridno ratovanje ima više značenja, ali u svakom slučaju znači strategiju mešanja različitih vrsta ratovanja. Može biti mešavina konvencionalnog i cyber ratovanja. Pojam hibridno ratovanje se često koristi da opiše napade nuklearnim, biološkim, hemijskim, improvizovanim oružjem i informacionim ratovanjem. Pojam hibridno ratovanje može biti korišćen da opiše fleksibilnu i kompleksnu dinamiku modernog borbenog prostora koji zahteva vrhunski prilagodljive i elastične odgovore. Trenutno, ne postoji univerzalno prihvaćena definicija hibridnog ratovanja. Neki autori tvrde da je termin suviše apstraktan, a drugi da se termin odnosi na neregularne metode u borbi protiv, uobičajeno, superiornog neprijatelja. U suštini termin je prihvaćen u vojnostručnoj literaturi najvećeg broja zemalja u svetu (na primer: SAD - Hybrid warfare, Rusija - Gibridnaя voйna, Srbija - Hibridno ratovanje itd.).
} 
Cilj rada je da se ukaže na značaj upotrebe društvenih mreža u hibridnom ratovanju, jer se moć ljudi nekontrolisano prelila iz njihovih kabineta, kancelarija i radnih soba na lokalnu, regionalnu i globalnu „scenu“ koristeći društvene mreže.

\section{Društvene mreže}

Društvene mreže predstavljaju vrstu internetskog servisa, koji se najčešće kreira u obliku platforme, aplikacije (prozora) ili web stranice koja je, prvenstveno, namenjena za međusobno povezivanje i komunikaciju između korisnika. Prvi oblici društvenih mreža pojavili su se devedesetih godina 20 . veka. Na internetu se mogu pronaći podaci koji ukazuju da je prvi sajt koji je imao karakter društvenih mreža stvoren 1997. godine „Six Degrees“. On je omogućavao korisnicima da prave profile, postavljanje fotografija i komunikaciju sa drugim korisnicima. ${ }^{3}$

Istraživanje u akademskoj sredini je pokazalo da društvene mreže funkcionišu na više nivoa, počevši od porodice do nivoa nacije, i da igraju kritičnu ulogu u određivanju načina na koji će se neki problemi rešiti, kako će organizacije funkcionisati, i stepen do koga će pojedinac uspeti u dostizanju individualnih ciljeva. Analiza društvene mreže posmatra društvene odnose u terminima „čvorova“ $i$ „veza“. Čvorovi su individualni akteri unutar mreže, a veze su njihovi međusobni odnosi. U svojoj najjednostavnijoj formi društvena mreža je mapa svih relevantnih veza između čvorova koji se proučavaju. Mreža može da se iskoristi i za određivanje društvenog kapitala individualnih aktera. Ovi koncepti se često prikazuju u vidu dijagrama društvene mreže, gde su čvorovi tačke a linije veze.

Društvena mreža (takođe i socijalna mreža) je društvena struktura sastavljena od pojedinaca (ili organizacija) koji se nazivaju „čvorovi“, a koji su povezani jednim ili više specifičnih tipova međuzavisnosti, kao što su vrednosti, vizije, ideje, finansijski interesi, prijateljstvo, srodstvo, zajednički interes, finansijska razmena, nedopadanje, seksualni odnosi, ili odnosi poverenja, znanja ili prestiža. Rezultujuća struktura često može da bude veoma kompleksna. ${ }^{4}$

Društvene mreže su sve popularniji način za komunikaciju putem interneta, i u sve većoj meri zamenjuju pisanje imejlova. Činjenica da čovek kao jedinka ne može sam opstati na planeti primorava ljude da tragaju za prijateljima. Svaki čovek želi da bude socijalno prihvaćen, želi da ga neko sasluša i da sa nekim deli mišljenje, sreću i tužne trenutke. Zahvaljujući društvenim mrežama, druženje i sticanje novih poznanstava nikada nije bilo jednostavnije i brže. Čak, iako je čovek stidljiva i introvertna osoba, to zna samo on, ali ne i neko sa druge strane ekrana i to je jedna od glavnih karakteristika društvenih mreža.

Servisi za društvene mreže fokusirani su na stvaranje zajednice istomišljenika ili povezivanje određene grupe ljudi prvenstveno putem interneta. Ponekad to mogu biti i prijatelji, osobe iz akademske zajednice, škole, preduzeća, udruženja, regioni itd.

Danas, društvene mreže nude raznovrsne sadržaje, od sklapanja prijateljstava, pregledavanja videa i fotografija, do onlajn trgovina (tzv. onlajn tržišta). Ujedno, društvene mreže su postale i predmet istraživanja psihologa, ekonomista i drugih stručnjaka kao spe-

\footnotetext{
${ }^{3}$ www.xxzmagazin.com/evolucija-drustvnenog-povezivanja, 17.06.2018.

${ }^{4}$ www.sr.wikipedija.org/sr/drustvena_mreza, 17.06.2018.
} 
cifičan fenomen današnjice. Trenutno, društvene mreže su u najvećoj meri besplatne, a samo neke od njih naplaćuju dodatne usluge. Jedini preduslov za njihovo korišćenje je (što brža) internet veza, a ponegde i periferni uređaji poput web kamere ili headseta.

Sadržaj korišćenja društvenih mreža je veoma raznolik. Društvene mreže se, najčešće, koriste za: komunikaciju između korisnika (razmenu poruka, razgovore i slično), opšte i stručno obrazovanje (studenti provode sve više vremena na društvenim mrežama tražeći informacije o fakultetskim predavanjima i komentarišući s kolegama i profesorima sadržaje koje pripremaju za ispit, gledaju video sadržaje kako bi olakšali učenje i uveli interaktivne sadržaje koji se lakše i brže pamte i slično), razvoj poslovanja (sve više kompanija posvećuje značajnu pažnju svojim prezentacijama na društvenim mrežama), informisanje i drugo.

Posmatrano iz bezbednosnog ugla, postoje izvesni indikatori da su se za formiranje nekih društvenih mreža angažovale i određene obaveštajne službe. Dugo vremena se izbegavalo da se javno govori o ovoj činjenici, sve dok nije nastupilo stanje otvorenog ispoljavanja globalnih protivrečnosti i nagli prelaz u sferu informacionih sukoba koji su poprimili oblike sajber i hibridnog ratovanja.

Davno su prošli dani kada se na društvene mreže gledalo kao na gubitak dragocenog vremena. Danas su socijalni mediji veliki biznis, a kompanije se nadmeću da ovim putem privuku što više kupaca i spremne su za to dati i mnogo novca. Mesečni broj aktivnih korisnika najvažniji je u ovom poslu i ključni je indikator popularnosti, ali i vrednosti određene mreže.

Mnogobrojna istraživanja o učestalosti korišćenja društvenih mreža, pokazala su da ih najviše koriste mladi, a posebno populacija starosne dobi između 15 i 50 godina. Najpopularnije društvene mreže su se menjale godinama, a može se očekivati da će i dalje doživljavati promene kako vreme bude prolazilo. Mnoge današnje trendove će zameniti novi. Prema dostupnim istraživanjima, najpopularnije društvene mreže su: Fejskbuk (Facebook), Tviter (Twitter), Viber (Viber), Skajp (Skype), Votsap (WhatsApp), Instagram (Instagram), Jutjub (YouTube), Linkedln, Xing, EduClipper, Pinterest i druge. Navedene društvene mreže moguće je svrstati u sledeće kategorije: mreže za društveno povezivanje, mreže za deljenje multimedijalnih sadržaja, informativne društvene mreže, profesionalne mreže i društvene mreže za hobi i interesovanja.

Društvena mreža „Fejsbuk“. Fejsbuk (Facebook) je internet stranica koja služi kao servis za društvenu mrežu. Počela je sa radom 4. februara 2004. godine kao servis za društveno umrežavanje na univerzitetu Harvard u Bostonu. Ova internet stranica, na koju se svako može učlaniti, nalazi se u vlasništvu istoimenog preduzeća (Facebook, Inc.) koje i upravlja njime. Njegovi korisnici se mogu pridruživati u mreže koje su organizovane po gradovima, školama i regionima radi povezivanja i komunikacije sa drugim ljudima. Takođe, ljudi mogu dodavati prijatelje, slati im poruke, a mogu i postavljati nove podatke u svoje profile, postavljati komentare, biti članovi određenih fejsbuk grupa i fan stranica.

Fejsbuk je stvorio Mark Zakerberg ${ }^{5}$ dok je bio student na univerzitetu Harvard. Prema podacima sa sajta, sredinom 2012. godine Fejbuk je imao više od milijardu i 200 miliona korisnika. Na ovoj mreži nalazi se preko 10 milijardi aplikacija, što znači da na svakog korisnika dolazi oko 10 aplikacija, i svakog dana stiže in sve više.

\footnotetext{
${ }^{5}$ https://sr.wikipedia.org/wiki/Mark_Zuckerberg - Mark Zakerberg (engl. Mark Zuckerberg) je američki programer i preduzetnik jevrejskog porekla. Za vreme studija na univerzitetu „Harvard“ (Harvard) stvorio je „Fejsbuk“, internet stranicu koja služi kao servis za društvenu mrežu.
} 
Fejsbuk je, prema rečima osnivača Marka Zakerberga, zamišljen tako da se putem interneta povežu oni ljudi koji se već poznaju u stvarnom životu, za razliku od sličnih web servisa. Kao što početna stranica Fejsbuka kaže, on omogućuje korisnicima povezivanje i socijalizaciju s ljudima koji su im bliski i koji rade, studiraju i žive oko njih. ${ }^{6}$ Mnogi koriste Fejsbuk upravo kako bi ostali u kontaktu sa svojim prijateljima ili rodbinom. Ovaj web servis je potpuno besplatan za sve korisnike, a ostvaruje prihode od sponzora i oglašavanja putem reklama koje se pojavljuju uz svaki profil, bez obzira što ga mnogi zloupotrebljavaju i u komercijalne svrhe.

Fejsbuk je dobar za promovisanje događaja, održavanje ljudi oko nekog zajedničkog cilja, promovisanje neke akcije (naročito od strane poznatih ljudi), i uopšte kao deo neke virtualne marketinške ili propagandne akcije. Ma koliko banalno izgledale neke organizacije, počev od pokreta, grupa i akcija, postoje i one koje mogu da utiču na kreiranje javnog mišljenja, jer imaju svoje stranice na Fejsbuku.

Društvena mreža „Tviter“. Tviter (Twitter) je besplatna društvena mreža i mikrobloging servis koji omogućava svojim korisnicima da čitaju tuđe, i šalju svoje mikrotekstualne unose, takozvane „tvitove“ (ograničenje jednog „tvita“ je do 140 slova). Zbog jasne forme i obima poruke na 140 karaktera, Tviter je izuzetna forma za brzo širenje kratkih i jasnih obaveštenja. Obaveštenja podrazumevaju informacije o korisničkim servisima, tehničkoj podršci, upravljanja različitim situacijama, raznim akcijama, promocijama i slično. Registrovani korisnici mogu čitati i slati svoje „tvitove“ dok ih oni koji nisu registrovani mogu samo čitati. Korisnici mogu pristupiti servisu putem web stranice, SMS-a ili mobilnih aplikacija. Tviter je društvena mreža slična Fejsbuku, ali bez slika, jer se pišu samo statusi. Mnogi programeri smatraju, da suština Tvitera nije u praćenju zanimljivih i simpatičnih lica, već ostvarivanje kontakta sa ljudima od kojih se može čuti korisna informacija.

Tviter je u suštini više informaciona nego društvena mreža jer, pored okupljanja, ljudima prvenstveno omogućava praćenje i pružanje korisnih informacija iz različitih oblasti društvenog života. Na primer, ako korisniku Tvitera zatreba pomoć za rešavanje nekog problema, najbolji način je da to napiše na mreži i brzo će se javiti neko ko ima rešenje. Pored navedenog, praksa korišćenja raznih društvenih mreža je pokazala, da se nove vesti i informacije najpre prošire na Tviteru, što je posebno karakteristično za sferu političkog i poslovnog života. Očigledno, Tviter je danas moćno sredstvo za kontrolisanje publiciteta i odnosa sa javnošću, što koriste političari (njihove organizacione celine za odnose sa javnošću) i velike međunarodne kompanije (poznati svetski brendovi).

Društvena mreža „Viber“. Viber ili Vajber (Viber) je aplikacija za pametne telefone koja korisnicima omogućava pozive i slanje besplatnih SMS poruka. Za razliku od ostalih VolP (Voice over Internet Protocol) servisa koji pružaju usluge, kao što je Skajp, Viber ne zahteva korisnički račun, te omogućuje besplatan poziv prema svim mobilnim i fiksnim mrežama, gde je softver instaliran na uređaj.

\footnotetext{
${ }^{6}$ Koliko je Fejsbuk "zarazan" i koliko je postao neizbežan deo ljudskih života najbolje potvrđuje činjenica da oko $70 \%$ korisnika koristi ovu mrežu svakog dana (69\% u Crnoj Gori, 71\% u Srbiji i Bosni i Hercegovnini, $72 \%$ u Sloveniji, 73\% u Makedoniji, 75\% u Hrvatskoj) www.ec.europa.eu/epale/hr/blog/koliko-smo-digitalni-statistikaupotrebe-digitalnih-tehnologija-u-srnoj-gori-i-u-regionu-u-2017, 10.06.2018.
} 
Viber je jedan od najpopularnijih, ako ne i najpopularniji softver (software) za pozive, tekstualne poruke i razgovore uopšte. Dostupan je na svim mobilnim platformama, a najlepša stvar kod njega je što korisnicima uopšte ne treba nikakav telefonski provajder. Ova društvena mreža se sinhronizuje sa telefonskim imenikom, tako da korisnik ne treba da dodaje kontakte u odvojenom imeniku. Softver Vibera ne prihvata reklamiranje i garantuje da će pozivi i slanje poruka uvek biti bez reklama, ne troši bateriju i ne zauzima memoriju uređaja, tako da se pozivi i poruke uvek mogu primati.

Zbog brzine i kvaliteta komunikacije, Viber je veoma pogodan za formiranje grupa sa zajedničkim interesima i srodnim ciljevima. Ovakve grupe, vrlo često su predmet proučavanja obaveštajnih službi, a posebno radi praćenja bezbednosno interesantnih pojedinaca.

Društvena mreža „Skajp“. Skajp (Skype) je program za brzo internet dopisivanje. To je društvena mreža koja korisnicima omogućava besplatan razgovor preko interneta, uz podrazumevanu komunikaciju putem razmene kratkih poruka i ostalih informacija.

Skajp je jedna od prvih društvenih mreža koja je omogućila korišćenje i video poziva. Upravo zato što je besplatna, ova društvena mreža je postala veoma popularna, jer omogućava razgovore sa licima u svim krajevima sveta koji su pokriveni internet mrežom. Sposobnost korišćenja audio i video razgovora sa više prijatelja od jednom (tzv. konferencijski pozivi), kao i istovremenog slanja fajlova (slike, dokumenti i slično) sagovornicima, uvrstila je Skajp u red najpopularnijih društvenih mreža.

Za razliku od većine društvenih mreža, Skajp ima i opcije koje se naplaćuju, ${ }^{7}$ kao što je pozivanje brojeva mobilne i fiksne telefonije, što zahteva i dopunu kredita na nalogu.

U periodu nastanka do danas, Skajp je doživeo mnogobrojne izmene, pre svega na polju video poziva i mrežne tehnologije. U zadnjih par godina, inovacije na Skajpu su usmerene na zaštitu informacija, jer su mnoge zainteresovane strane, raznim kanalima, uspevale da detektuju signale i prikupe značajne podatke za unapređenje sopstvenog poslovanja.

Sposobnosti Skajpa su postale značajne za tržišnu ekonomiju i poslovni marketing, a između ostalog i za rad obaveštajno-bezbednosnih službi, jer su omogućile realizaciju jednovremenih video konferencija sa više lokacija u različitim delovima sveta.

Društvena mreža „Votsap“. Votsap (WhatsApp) je platformska mobilna aplikacija koja omogućava korisnicima da međusobno razmenjuju poruke. Votsap je dostupan na svim mobilnim android uređajima i omogućava korisnicima slanje poruka. Osim slanja poruka korisnici aplikacije mogu kreirati grupe i međusobno slati neograničen broj slika, audio poruka, video zapisa i trenutne lokacije. U jednom od novijih ažuriranja aplikacija omogućava i govorne pozive. Votsap se skoro u potpunosti integriše sa uređajem na koji je instaliran, ne samo da ima pristup imeniku i galeriji slika, već je aplikacija konstantno aktivna u pozadini. Pokreće se startovanjem telefona i nije se potrebno na nju prijavljivati. $U$ konkurenciji između Fejsbuk mesindžera, Skajpa i Vajbera, Votsap se uz veliki trud svojih osnivača i ljudi zaduženih za njegov razvoj uspeo probiti na vrh.

$U$ poslednjih nekoliko godina, Votsap je postao predmet interesovanja raznih bezbednosnih službi, pre svega službi unutrašnje kontrole, jer su nakon uspešnog praćenja razmena poruka presečeni mnogi švercerski kanali i trgovina ljudima.

\footnotetext{
${ }^{7}$ Uplata kredita na Skajpu je minimalno 10 evra, a cene usluga su izuzetno niske. Pozivi preko Skajpa na mobilne ili fiksne telefone, naplaćuju se po oko 2 centa (oko 2 dinara) po minutu. www.internet-srbija.com, 05.06.2018.
} 
Društvena mreža „Instagram“. Instagram (Instagram) je besplatna aplikacija koja svojim korisnicima omogućava obradu i deljenje fotografija na društvenim mrežama (Fejsbuk, Tviter, Tambler, Fliker itd.) putem Android i drugih platformi.

Instagram je originalni servis za preradu fotografija, ali je u junu 2013. godine uvedeno i objavljivanje video-snimaka na istom servisu, trajanja do 15 sekundi. Pre objavljivanja fotografija, korisnik može da ih promeni uz određene filtere. Ti filteri menjaju boju fotografija, određeni dodaju ramove fotografiji itd. Najpopularniji filteri na Instagramu su: Amaro, Mayfair, Rise, Valencia, Hudson, X-Pro II, Sierra, Willow, Lo-fi, Earlybird, Sutro, Toaster, Brannan, Inkwell, Walden, Hefe, Nashville i Kelvin.

Prema istraživanju britanskog kraljevskog društva za javno zdravlje, Instagram je najštetnija društvena mreža za mentalno zdravlje mladih, dok Jutjub (YouTube) ima najpozitivniji uticaj. Instagram služi za objavljivanje fotografija i broji oko 700 miliona naloga, a najlošije deluje na osobe ženskog pola i to uglavnom tako što ih navodi da porede sebe sa nerealnim predstavama i filtriranim verzijama stvarnosti. Kod mladih devojaka i žena Instagram stvara osećaj da njihovo telo nije dovoljno dobro, jer ljudi obrađuju svoje slike u fotošopu da bi izgledali savršeno. Ovakve činjenice ukazuju na potrebu mladih korisnika da se na virtuelni način izbore sa osećanjima nesavršenosti i anksioznosti što ih u određenim stresnim situacijama može dovesti u zabuludu i gubitak veze sa stvarnošću.

Instagram nepovoljno utiče na predstavu o telu, na obrasce spavanja i stvara kod korisnika strah da nešto propuštaju, ali je, s druge strane, dobar za izražavanje sopstvene ličnosti i analizu pojedinaca od strane dela zainteresovanih strana (na primer, tvoraca društvenih mreža, međunarodnih političkih i bezbednosnih organizacija i slično).

Društvena mreža Linkedln je poslovna društvena mreža koja je namenjena povezivanju poslodavaca i ljudi koji traže posao. Ova mreža je nastala sa ciljem efikasnog predstavljanja profesionalnih sposobnosti njenih članova, povezivanja i što bržeg spajanja poslodavaca sa lovcima na poslove. Linkedln je, pored ostalog, najveća svetska profesionalna poslovna društvena mreža na kojoj poslovni ljudi razmenjuju iskustva, učestvuju u raspravama, dele zanimljive sadržaje i, naravno, pronalaze nove poslodavce. ${ }^{9}$ Ono što izdvaja Linkedln od ostalih društvenih mreža je njegova strogo poslovna orijentacija. Ova mreža može pomoći i pojedincima da se izgrade i jačaju kako bi se promovisali kao stručnjaci u svojoj oblasti. To je razlog što je kreiranje profila jedan od najznačajnijih i početnih koraka koje je potrebno preduzeti. Bitni elementi ličnih profila su: profesionalna biografija, zaglavlje, sadašnje radno mesto, obrazovanje, preporuke, veb sajtovi, tviter, korisnička URL adresa, rezime i specijalnosti. Korišćenje Linkedln grupa je dobar način da se pronađe sadržaj koji će privući pažnju zainteresovanih strana, a time i obaveštajno-bezbednosnih službi.

U proteklih par godina, prvobitna namena društvenih mreža znatno se promenila, jer se uočila mogućnost njene masovne primene u sferi bezbednosti, počevši od pojedinca pa do širih društvenih zajednica. Javna je tajna da su tvorci društvenih mreža počeli da prave softverske programe za prisluškivanje, prevashodno usmerene na ciljne ličnosti i

\footnotetext{
${ }^{8}$ http://www.politika.rs , 28.05.2017 - Studija je obuhvatila 1.500 mladih od 14 do 24 godine i ispitivalo se kako određena društvena mreža utiče na njihovo opšte zdravlje, anksioznost, depresiju, identitet i predstavu o njihovom telu.

${ }^{9}$ www.sr.wikipedija.org/sr/Linkedln, 17.06.2018.
} 
grupe. Izrada ovakvih programa počiva na mnogobrojnim slabostima i ranjivosti čovekovog bića, jer ulazi u njegovu podsvest nastojeći da ga potpuno istraži radi dalje kontrole i potpune manipulacije.

Špijunski programi sve više „lutaju“ društvenim mrežama tragajući za informacijama o aktuelnim ključnim ličnostima počevši od pojedinca, pa do celih interesnih društvenih grupa ili organizacija. U želji za ostvarivanjem dugoročnih geopolitičkih ciljeva, velike svetske sile i njihove megakorporacije, tajno finansiraju izradu špijunskih softvera koji se sve više usmeravaju na najmlađe interesne grupe, pre svega u tehnološki nerazvijenim zemljama, radi opitovanja, kreiranja psiholoških profila ličnosti i njihove pripreme za uspostavljanje budućih političkih sistema prema sopstvenom ukusu.

Analiza društvenih mreža (teorija mreža) je postala ključna tehnika u modernoj sociologiji, antropologiji, sociolingvistici, geografiji, socijalnoj psihologiji, studijama o komunikaciji, informatičkim naukama, organizacionim naukama, ekonomiji i biologiji, a takođe kao i popularan predmet istraživanja i u drugim naučnim oblastima.

\section{Hibridno ratovanje}

Pretnje po lokalnu i regionalnu bezbednost u poslednjih desetak godina inicirale su teoretičare bezbednosti, posebno vojne teoretičare, da pišu i govore o novoj-staroj „formi sukoba“ - hibridnom ratovanju i o novim pretnjama po bezbednost - „hibridnim pretnjama“.

Nemogućnost jasnog definisanja hibridnih pretnji, ${ }^{10}$ opravdava se u činjenici da je u svim nedavnim sukobima konstantno primenjena asimetrija upotrebe snaga i sredstava, van poznatih normi i pravila ratovanja, a pogotovo što brza pobeda nad protivnikom nije preko neophodna.

U dostupnoj literaturi, često se pominje da su savremeni sukobi hibrid nepravilnog i konvencionalnog ratovanja u veoma složenom bezbednosnom okruženju. Dakle, kombinuju se nenasilne i nasilne metode primenom savremene komunikacione tehnologije i borbenih sistema, uzimajući u obzir aktuelnu geopolitičku situaciju, a radi postizanja željenog krajnjeg stanja. ${ }^{11}$ Ovakvo stanje usložnjava pravovremeno prepoznavanje i jasnu identifikaciju hibridnih pretnji i pripremu i adekvatan odgovor na identifikovane pretnje.

Iz analize sukoba, moguće je zaključiti da hibridno ratovanje može predstavljati koncept koji na originalan način obuhvata primenu asimetrija, standardnih i nestandardnih taktika, tehnika i procedura u okviru meke i tvrde moći za dostizanje željenog (političkog) krajnjeg stanja. Ovde nije reč o novom ratovanju ili novoj formi sukoba već o kombinaciji svih dosadašnjih formi sukoba.

Hibridni rat zahteva vreme jer se upotreba tvrde moći očekuje nakon neuspeha meke moći. Klauzevic je rekao da je rat produženje politike drugim sredstvima, međutim današnji razvoj tehnologije $\mathrm{i}$ iskustvo od preko dva milenijuma je dovelo do toga da rat može da traje duže nego što to nacija može da spozna. Tehnološki razvoj naoružanja i

\footnotetext{
${ }^{10}$ Hibridnim pretnjama se nastoje iskoristiti slabosti pojedine države i često ugroziti temeljna demokratska prava i slobode. Zajednički okvir za suzbijanje hibridnih pretnji - odgovor Evropske unije, Bruxelles, 06.04. 2016. str. 3.

${ }^{11}$ Željeno krajnje stanje u poslednje vreme sve manje podrazumeva fizičko uništenje ili porobljavanje određenih subjekata u sukobu već oblikovanje percepcije i mišljenja odreženih subjekata - moderno porobljavanje.
} 
vojne opreme neposredno utiče na razvoj taktika i procedura, a posredno i na evoluciju ratovanja. Pojavom robotizovanih borbenih sistema, različitih formi informacionog delovanja i sajber napada, stvorila se mogućnost upravljanja borbenim dejstvima i delovanje sa daljine odnosno mogućnost „daljinskog“ ratovanja, u kome nema neposrednog (borbenog) dodira sukobljenih strana.

Komentarišući geopolitičku situaciju u azijskom regionu vojni stručnjaci i analitičari tvrde da je hibridni rat već počeo, ali se ne vodi vojnim (borbenim) sredstvima, već se određenim delovanjem u informacionom, sajber, ekonomskom i političkom prostoru pokušava destabilizacija određenih država i regiona. Sintagma hibridni rat nije definisana, pa je zbog toga na teoretičarima da na osnovu iskustava iz prakse izvrše objašnjenje hibridnog rata. Međutim, potraga za definicijom hibridnog ratovanja ukazuje na slične probleme koji su se pojavljivali pri definisanju „terorizma“.

Globalna strategija Evropske unije o spoljnoj i bezbednosnoj politici prikazuje lokalne, regionalne i globalne težnje, ali i bezbednosne izazove, rizike i pretnje. U kontekstu bezbednosti pominje se, između ostalog, da hibridne pretnje predstavljaju veliki izazov za bezbednost građana i teritorije. Hibridne pretnje nisu definisane, a takođe nisu jasno navedeni postupci koji bi bili u kontekstu hibridnih pretnji. Time je stvoren određeni prostor za naučnu i stručnu raspravu o tendencijama određenih država i regiona u kontekstu hibridnog ratovanja.

Za ostvarivanje uspeha u hibridnom ratu od velikog je značaja pravovremeno prepoznavanje i identifikacija hibridnih pretnji. Za pravilno prepoznavanje i identifikaciju hibridnih pretnji, što je jedan od najvažnijih uslova za uspeh u hibridnom ratu, neophodna je pravilna procena operativnog okruženja. ${ }^{12}$

U svakodnevnom životu i funkcionisanju ljudi i društvenih organizacija, jedna naizgled nevažna situacija može pod određenim okolnostima predstavljati hibridnu pretnju, pa je stoga veoma važno odrediti indikatore na osnovu promena u operativnom okruženju koji ukazuju na hibridnu pretnju. Procena operativnog okruženja u hibridnom ratu je veoma kompleksna iz razloga teškog utvrđivanja indikatora u pojedinim elementima operativnog okruženja koji ukazuju na hibridnu pretnju.

Pojedini autori definišu hibridnu pretnju kao: „Hibridna pretnja, u kontekstu nacionalne bezbednosti, može se shvatiti kao svaki izazov koji pod određenim okolnostima menja oblik i kao takav može ugroziti nacionalne interese određene države“. ${ }^{13}$ Kao prilog ovoj tvrdnji autori navode sledeće primere: migrantska kriza pod određenim okolnostima može ugroziti bezbednost države i njenih građana, mirni protesti pod određenim okolnostima mogu prerasti u pokret za rušenje ustavnog poretka određene države, delovanje nevladinih organizacija u određenim okolnostima može se razviti u relevantan politički faktor koji se otvoreno bori, podržava i obrazuje neke nove vrednosti koje u suštini urušavaju osnovne koncepte lokalnog društva i mogu „negativno“ uticati na nacionalne vrednosti određene države i predstavljati hibridnu pretnju itd.

Nagomilavanje oružanih sastava duž granice određene države u određenoj geopolitičkoj situaciji može predstavljati vežbu preventivnog razmeštanja snaga, a u određenoj situaciji može predstavljati hibridnu pretnju. Rad pojedinih regionalnih i globalnih medija, kao i inter-

\footnotetext{
${ }^{12}$ FM 3-0 Operations, Headquarters Department of the Army, Washington, DC, 27 February 2008. page 15.

${ }^{13}$ Terzić, M, i dr, Hibridno ratovanje i globalne tendencije Evropske unije, 12. Međunarodno savetovanje Rizik i Bezbednosni inženjering, Kopaonik, 2017. str. 47 - 52.
} 
net komunikacija u zoni operacije pod određenim okolnostima može predstavljati hibridnu pretnju. Razvoj naoružanja i opreme koja ima više modova upravljanja i njihovo testiranje u uslovima sličnim zoni operacije može predstavljati hibridnu pretnju i drugo.

Navedeno ukazuje na kompleksnost procene operativnog okruženja u konceptu hibridnog ratovanja i teškoću jasnog utvrđivanja indikatora hibridnih pretnji. Koncepti hibridnog ratovanja su različiti pa u skladu sa tim i u pojedinim fazama koncepta hibridnog ratovanja, procena pojedinih elemenata operativnog okruženja ima različit značaj. Na primer: u početnoj fazi hibridnog rata od velikog je značaja pravilna procena informacionog okruženja (identifikovanje promena u informacionom okruženju) i na osnovu te procene određivanje indikatora ugrožavanja bezbednosti određene države (delovanje radija i televizije protiv državnog rukovodstva ili upotreba globalnih medija i društvenih mreža za pozivanje na okupljanja, proteste itd.), dok u „završnoj fazi“ hibridnog rata, ukoliko se primenjuje tvrda moć, od velike je važnosti procena ekonomskog i vojnog elementa operativnog okruženja radi utvrđivanja indikatora koji će ukazivati na trošenje resursa, dužinu trajanja sukoba i slično.

\section{Upotreba društvenih mreža u hibridnom ratovanju}

Dosadašnja iskustva iz minulih ratova u 21. veku, koji se mogu svrstati u ratove po hibridnom konceptu, pokazuju da je teško odrediti trenutak sa „vidljivim manifestacijama“ kada će intenzivna primene meke moći preći na primenu tvrde moći. ${ }^{14} \mathrm{U}$ ovakvim ratovima, posebno je karakteristična masovna upotreba informacionog prostora (posebno sajber prostora) za napade na određene funkcije države, ali i za motivisanje i mobilisanje određenih subjekata na okupljanja, proteste i pobune, putem društvenih mreža.

Ubrzan razvoj informacionih tehnologija, uslovio je pojavu na stotine društvenih mreža koje su omogućile međusobno povezivanje i interakciju ljudi u različitim oblastima. Uvažavajući namenu i specifičnosti svake društvene mreže i celih grupa društvenih mreža, uočava se njihov zajednički imenilac koji je sadržan u skrivenom slanju masovnih poruka radi ostvarenja krajnjih namera sukobljenih strana.

Globalizacija postaje sve više zavisna od efekata primene društvenih mreža, što potvrđuje višestruki porast njenog značaja u zadnjih par godina. Tačnije, društvene mreže polako postaju klackalica informacija na globalnom nivou. Na koju stranu i u čiju korist će prevagnuti, zavisi od efekata meke moći koje žele ostvariti (ne)državni subjekti. Navedeni značaj i efikasnost društvenih mreža u oblikovanju percepcije („ispiranju mozgova“) svetske populacije, pobudila je interesovanje za novi (hibridni) koncept sukoba kod svih političkih, ekonomskih, vojnih i drugih planera koji su bili zagovornici isključivo primene tvrde moći u sukobu.

Među brojnim taktikama koje su specifične za hibridno ratovanje (sa njihovim ispoljavanjem na operativnom i strategijskom nivou), upotreba društvenih mreža zauzima posebno

\footnotetext{
${ }^{14}$ Tvrda moć predstavlja, pretežno, vojnu i ekonomsku snagu radi uticaja na ponašanje država ili nedržavnih subjekata ili radi direktne promene toka događaja u sukobu. Meka moć predstavlja sposobnost uticaja na druge da usvoje željeni pravac delovanja kroz kurtuloroški i ideološki uticaj ili podsticanjem na promene. Sfere uticaja meke moći mogu biti: kultura (npr. promovisanje ili podrška određene kulture koja je privlačna drugima, vrednosti (koje se očigledno i iskreno primenjuju), spoljna politika (kada je drugi smatraju legitimnom), inkluzivno delovanje radi rešavanja određenih problema (npr. radi zaštite nacionalnih manjina) i sl.
} 
mesto u sferi informacionog ratovanja. Ovako visoku poziciju društvene mreže su dobile, zbog ranjivosti intelekta savremenog čoveka. Tačnije, zahvaljujući napretku informacionih tehnologija i širokom spektru njihove upotrebe kroz koji se prožimaju svi oblici ljudske delatnosti, čovek kao pojedinac, grupe ljudi ili čitava društva postaju zavisnici od pravovremenosti informacija, nezavisno od toga da li se radi o lažima ili istinama. Upravo ovakvo kvantitativno utrkivanje društvenih mreža za povećanjem broja aktivnih korisnika, izazvalo je nove potrese u do skoro poznatoj informacionoj sferi ratovanja i otvorilo je široki dijapazon brzog lansiranja neistina i dezinformacija. U ovakvoj situaciji, poznati sistemi zaštite bezbednosti države i društvenih zajednica od psihološko-propagadnih dejstava postaju prevaziđeni i nužno traže nove mehanizme za suprotstavljanje narastajućem pritisku društvenih mreža koje izazivaju masovnu promenu raspoloženja nad ciljnim populacijama.

Zahvaljujući velikoj propusnoj moći informacija na internetu, upotreba društvenih mreža dotakla je sve bezbednosne aspekte jedne zemlje i opasno ugrozila: diplomatske aktivnosti; obaveštajne i kontraobaveštajne mere; razmenu informacija i saradnju u oblasti bezbednosti i odbrane na regionalnom i međunarodnom nivou; psihološko-propagandne i izviđačke aktivnosti; određena dejstva u sajber prostoru i zaštitu od dejstava u sajber prostoru; zaštitu infomacija od strategisjkog značaja; informisanje i strateške komunikacije; zaštitu ekonomskih i energetskih kapaciteta; jačanje nacionalnih i zajedničkih vrednosti (razvoj osnovnih ćelija društva kroz obrazovanje, kulturno uzdizanje i promovisanje zajedničkih vrednosti); zaštitu kritične infrastrukture; civilno-vojnu saradnju na lokalnom, regionalnom i nacionalnom nivou; konvencionalna borbena dejstva (od pešadijskih do protivterorističkih dejstava); specijalna dejstva i druge akcije.

Navedene oblasti, nisu posebno analizirane, ali ukazuju na niz načina, tehnika i procedura koje se mogu primeniti u hibridnom ratovanju. Poznata vojnička floskula „neprijatelj nikada ne spava“, u potpunosti važi za društvene mreže, jer su neprekidno aktivne, u statusu deklarisanih "prijatelja", ali se izuzetno brzo mogu upotrebiti za širenje dezinformacija i ostvarivanje "neprijateljskih namera". Faktor iznenađenja je ključ uspeha u širenju informacija putem društvenih mreža, a posebno ako se prethodno dobro pripreme i organizuju za korišćenje različitih instrumenata primene meke moći.

Nastupanje ere društvenih mreža, uočava se i po značaju koji im je dodeljen u pogledu dobijanja statusa opredeljujućeg činioca za klasifikaciju sukoba. Posmatrano sa aspekta hibridnog ratovanja, minule sukobe u prošlom i početkom ovog veka, možemo podeliti na dve globalne celine, period pre i period posle pojave društvenih mreža. Zavisno od vrste autora i načina shvatanja hibridnog ratovanja, graničnik između navedenih perioda, može se podešavati u rasponu od 2000. do 2010. godine. U tom periodu, u hibridnim ratovima koristi se široki dijapazon oružja, pri čemu nisu sva vatrena. Zahvaljujući kamerama u mobilnim telefonima i softveru za prepravljanje fotografija na svakom računaru, a takođe i nadmoći društvenih medija, informacioni kontekst je postao važan aspekt modernog ratovanja, što je i ilustrovano primerima u aktuelnim ratovima u Siriji i Ukrajini.

Većina autora se slaže, da se kao očigledni primeri upotrebe društvenih mreža u hibridnom ratovanju, mogu smatrati konflikti: 1) Sukob Izraela i Hezbolaha, 2) Sukob u Siriji, 3) Sukob u Ukrajini i 4) Pokušaj vojnog puča u Turskoj. 


\section{Sukob Izraela i Hezbolaha}

Koncept hibridnog ratovanja aktuelizovan je 2006. godine nakon sukoba između Izraela i Hezbolaha. Hezbolah se u Libanu 2006. godine borio protiv Izraela pomoću dobro obučenih ćelija koje su kombinovale propagandu, konvencionalne vojne taktike i rakete koje su lansirane iz gusto naseljenih civilnih područja, ostvarivši ono što su mnogi u regionu smatrali političkom pobedom.

Posebno je karakterističan pristup Hezbolaha u vršenju psihološko-propagandnih aktivnosti, gde su ne samo preko medijskih servisa i SMS poruka, već i preko ukradenih prvobitnih verzija Fejsbuka (prema nekim autorima i Tvitera), širili dezinformacije među sopstvenim i izraelskim stanovništvom. Indikativna su saznanja da su verzije navedenih društvenih mreža, upravo ukradene od izraelske vojske, koje je dobila kao pomoć od SAD radi sticanja prevlasti u informacionom prostoru.

Navedeni sukob prikazao je niz specifičnosti: sukob države i nedržavnog subjekta; sadejstvo gerilskih jedinica i regularnih trupa tokom protivtenkovskih i protivvazduhoplovnih dejstava na Izrael; afirmativno i u realnom vremenu prikazivanje snimaka uspešnih dejstava Hezbolaha, na više medija uključujući i sajber prostor; prikazivanje dejstava Izraela suprotno međunarodnim pravilima radi pridobijanja podrške islamske zajednice tokom trajanja sukoba; asimetrična upotreba sile; niz taktičkih iznenađenja i slično. Posebno je karakteristična situacija, da su po prekidu dejstava obe strane u sukobu proglasile pobedu.

Nakon sukoba ostala je činjenica da je Hezbolah dostigao postavljeni cilj i dobio "medijski" rat uspešno koristeći informacioni prostor, uključujući delovanje na globalnoj komunikacionoj mreži (internetu ili u sajber prostoru), pri čemu je upotreba začetaka društvenih mreža postavila znak pitanja u glavama mnogih vojnih stratega i teoretičara.

Mogućnosti Hezbolaha, kao nedržavnog subjekta, da koristi nove forme ratovanja, odjeknule su u islamskom svetu koji mu je vrlo brzo pružio nedvosmislenu podršku. U prilogu ovoj tvrdnji je podrška od Irana, koji je odmah tražio pokretanje rasprave u Ujedinjenim nacijama o Izraelu i njegovoj taktici borbenih dejstava protiv Hezbolaha i kršenju međunarodnih pravila ratovanja.

\section{Sukob u Siriji}

Bogata naftonosna polja i nagomilani međunacionalni problemi, uslovili su da se na Bliskom istoku rasplamsaju sukobi, uglavnom zasnovani na istorijskim činjenicama i izrežiranim scenarijima velikih svetskih sila. Sukob u Siriji, posebno u regionu Alepo, gde su se sukobile snage Sirijske armije, oružane snage Ruske Federacije, oružane snage SAD i Islamska Država, posledica je ostvarivanja određenih geostrateških interesa, ${ }^{15}$ a

\footnotetext{
${ }^{15}$ Sirija je značajna jer je trebalo da bude kraj terminala gasovoda između Irana i Iraka, koji bi dozvolio Iranu pristup evropskom tržištu i potpuno poništio režim sankcija. Konkurentski projekat je gasovod od Katara preko Saudijske Arabije, Jordana i Sirije do Evropske unije ili kao tečni gas preko Turske. Predsednik Sirije je odbio predlog Golfskog gasovoda zbog odanosti Iranu, zbog čega je na sebe navukao žestok hibridni rat. Luka Todorović, Milovan Milutinović, (12. maj 2016) Globalne tendencije i hibridni rat, SVAROG, str. 19.
} 
ispoljio je niz specifičnosti od intenzivne medijske kampanje, vođenja posrednih (eng. proxy) ratova, intenzivnog korišćenja sajber prostora za propagandu i vrbovanje terorista do upotrebe robotizovanih borbenih sistema.

Ovaj sukob novijeg datuma, predstavlja očigledan primer hibridnog ratovanja, gde su u fazi njegove pripreme društvene mreže odigrale jednu od odlučujućih uloga u narastanju međunacionalnih netrpeljivosti i lansiranju lažnih informacija.

U pripremnoj fazi sukoba, obaveštajne službe zapadnih zemalja, odigrale su presudnu ulogu na polju tehničko-tehnoloških dostignuća, pre svega kroz instaliranje špijunske mreže na ključnim mestima odlučivanja, uspostavljanje obaveštajno-operativnog rada i formiranje interesnih grupa na društvenim mrežama. Primenom metode postepenog sagorevanja svesti ljudi, obaveštajne službe zapadnih zemalja su uspele da inspirišu nacionalizam, ne samo kod vodećih političara, već i masovno među stanovništvom preko društvenih mreža prisećajući ih na minule istorijske sukobe i društvene protivrečnosti na prostoru Bliskog Istoka.

U sukobu u Siriji, Islamska država je masovno koristila društvene mreže, radi zastrašivanja svetske javnosti o posledicama koje mogu nastupiti u slučaju da se ne podrže njihovi ciljevi. Pored navedenog, društvene mreže su iskorišćene kao alat za javno pozivanje (regrutovanje) islamskih fanatika iz celog sveta da do dođu u Siriju i da se bore na Alahovom putu. Obostrano širenje dezinformacija od sukobljenih strana, proizvelo je informacioni haos u domaćoj i svetskoj javnosti, a medijske kuće prenosile su vesti koje su strogo cenzurisane i u funkciji interesa velikih sila. Spoznavši mogućnosti društvenih mreža, ubrzo je došlo do prestrojavanja dela medijske kampanje, što su posebno iskoristili teroristi Islamske države.

Nažalost, sukob u Siriji i dalje traje, a informacioni rat ne gubi na jačini. Primenjeni model hibridnog ratovanja u ovoj multietničkoj zemlji, opravdava upotrebu svih raspoloživih sredstava, od meke do tvrde moći, a sve u cilju kontrole njenih bogatih naftonosnih polja.

\section{Sukob u Ukrajini}

Neravnomerna raspodela svetskih bogatstava zasnovanih na prirodnim resursima, us-lovila je pažljivo planiranje kriza na Evroazijskom prostoru, prema već oprobanim receptima napravljenim u svrhu rasplamsavanja uglavnom etničkih i verskih sukoba. Sukob u Ukrajini (obojena revolucija, evromajdan) karakteriše intezivno korišćenje sajber prostora radi mobilizacije stanovništva za okupljanje i proteste kao i intenzivna propaganda radi smene postojećeg režima. Nakon sukoba u Ukrajini, SAD i EU su optuživale Rusiju za sprovođenje hibridnog rata u Ukrajini, naročito na Krimu. Evropska Unija u Globalnoj strategiji za bezbednost i spoljnu politiku i SAD u najnovijoj Strategiji nacionalne bezbednosti kao jednu od glavnih pretnji po bezbednost označila je Rusiju.

$\mathrm{Na}$ regionalnim bezbednosnim forumima vodila se i vodiće se debata o hibridnom ratu Rusije u Ukrajini, a takođe o hibridnom ratu SAD i Evropske Unije protiv Rusije. Evropska Unija i SAD su optuživale Rusku federaciju da je vodila hibridni rat primenom meke moći u Ukrajini što je rezultiralo pripajanjem poluostrva Krim Ruskoj federaciji. Pojedini teoretičari iz Rusije i Ukrajine optužuju „Zapad“16 da vodi hibridni rat protiv Rusije, koji ne obuhvata samo vojne operacije niskog intenziteta ili diverzantska dejstva u Donbasu, već i informacioni,

\footnotetext{
${ }^{16}$ „Zapad“ obuhvata Evropsku uniju i Sjedinjene Američke Države.
} 
diplomatski i ekonomski rat, uz objavljene i neobjavljene sankcije, poput zabrane kreditiranja i onemogućavanja ruskim kompanijama da dođu do najnovijih tehnologija.

U ovom sukobu, pored intenzivnih medijskih kampanja, društvene mreže su imale veliki ulogu u fazi pripreme ukrajinske i ruske javnosti za buduće događaje. Masovno širenje dezinformacija putem društvenih mreža, izazvalo je nepoverenje ukrajinske javnosti u političko i vojno rukovodstvo, što se i potvrdilo nakon pripajanja poluostrva Krim Ruskoj federaciji. Ovakvom sledu aktivnosti, znatno su doprinele istorijske činjenice, struktura stanovništva na Krimu i sumnje ukrajinskog stanovništva u mogućnost očuvanja jedinstva države.

Zahvaljujući društvenim mrežama, značajan deo ukrajinske javnosti je podržao težnje Rusije za ispravljanjem istorijskih grešaka, a pogotovo nakon pružanja oružanog otpora ruske manjine u Donbas regiji. Posebno su interesantni medijski materijali plasirani preko društvenih mreža, koji su prikazivali neorganizovanost, pad morala i dezerterstvo ukrajinskih vojnika. U takvim okolnostima besciljnog delovanja, politička i druga pomoć SAD i članica EU bila je uzaludna.

Države članice EU (Nemačka i Francuska) su i tokom 2015. godine ostale među ključnim međunarodnim subjektima u rešavanju ukrajinske krize. U tom smislu, bile su dosledne stavu da je Ruska Federacija (RF) izvršila nelegalnu aneksiju Krima i nelegitimno angažovanje oružanih snaga u rejonu Donbasa. Uprkos tome, cilj spoljnopolitičkog angažovanja EU na istoku Evrope bio je očuvanje primirja, suzbijanje ruske moći na svim poljima i traganje za političkim rešenjem krize.

Istovremeno, više puta su produžavane ekonomske sankcije Ruskoj federaciji, navodno zbog pripajanja Krima. Rezultat navedene odluke su veliki finansijski gubici i rast nezadovoljstva privrednika i građana u pojedinim članicama EU, koje su stoga pojačale pritisak na politički vrh u svojim državama da se sankcije ublaže ili čak i ukinu (za ukidanje se prevashodno zalagala Italija). Istovremeno, zemlje EU su nastojale da zaštite sopstvene finansijske i političke institucije od negativnog uticaja krize.

Radi dostizanja navedenih ciljeva, preduzete su mere na stvaranju kapaciteta za odgovor na hibridne pretnje. Shodno tome, kao nevojni odgovor na navodne informacione operacije Ruske federacije i organa vlasti u republikama Donjeck i Lugansk, početkom septembra 2015. godine je, u okviru Spoljnopolitičke službe EU (EEAS), formiran tim za brzo reagovanje na rusku propagandu pod nazivom East StratCom Team ${ }^{17}$. Takođe, vodi se debata u Evropskom parlamentu o nacrtu „Rezolucije o strateškim komunikacijama EU i kako se suprotstaviti propagandi koja dolazi iz trećih zemalja“, u kojoj se delovanje ruskih medija Sputnjik i televizija Raša tudej izjednačava sa propagandom terorista. Za suprotstavljanje delovanju ruskih medija predlagane su sledeće aktivnosti: blokiranje web stranica, blokiranje bankovnih računa, kontrola društvenih mreža i slično.

$\mathrm{Na}$ određenim sastancima EU tokom 2015. godine izveden je zaključak, da je ukrajinska kriza potvrdila „ograničenu“ moć EU da nevojnim (spoljnopolitičkim) sredstvima deluje na istočnim granicama. $U$ skladu sa navedenim, tokom juna 2015. godine održana je prva neformalna konferencija Međunarodnog vojnog štaba NATO i Vojnog štaba EU kao deo NATO-EU strateškog dijaloga koji je uspostavljen 2003. godine. Cilj je bio unapređenje komplementarnosti rada štabova na projektima koji se odnose na hibridno ratovanje, sajber odbranu i izazove koji postoje na jugu i istoku Evrope.

\footnotetext{
${ }^{17}$ The East StratCom Team je deo admitinstracije Evropske unije čiji je zadatak proaktivna strateška komunikacija i promovisanje politike i aktivnosti EU u istočnom delu (Jermenija, Azerbejdžan, Belorusija, Gruzija, Moldavija i Ukrajna, a šire i Rusija).
} 


\section{Pokušaj vojnog udara u Turskoj}

Dugogodišnjem nezadovoljstvu turskog naroda vladavinom Redžepa Taipa Erdogana, prethodila je izbeglička (migrantska) kriza, američki izbori, novi i sve učestaliji talasi terorističkih napada širom sveta, kao i mnogobrojna politička previranja oko sukoba i budućeg statusa Islamske države i Kurdistana. Priprema i izbijanje vojnog puča je odraz ogromnog nezadovoljstva turskog naroda i samo jedan od prelomnih momenata u daljoj vladavini Redžepa Taipa Erdogana. Pojedini stručnjaci iz oblasti bezbednosti smatraju da je puč režiran kako bi Erdogan mogao da novonastalu situaciju iskoristi za obračun sa svim neprijateljima u vojsci i uspostavi predsednički sistem, sa sultanističkim pretenzijama.

Bez obzira na dugi period priprema, vojni puč u Turskoj je propao, usled loše organizacije i podele među pučistima, kao i brojnim pogrešnim koracima. U celom toku dešavanja između petka i subote (15/16. jul 2017. godine), društvene mreže su odigrale veoma važnu ulogu, i to nije prvi put da društvene mreže pomognu artikulaciju društvenih protesta, pa čak i smenu političkih režima, što potvrđuje i Arapsko proleće.

Prema dostupnim informacijama, pučisti su bili sačinjeni od vojnih oficira srednjeg ranga koji su pokušali da izvedu klasičan vojni udar na taktičkom i operativnom nivou, ali nisu razmišljali na strateškom nivou. Zatvorili su ključne saobraćajne linije, pokušali da zauzmu skupštinu i predsedničku palatu, a izveden je i pokušaj kidnapovanja visokih državnih zvaničnika uključujući predsednika Erdogana i vojni vrh. Pučisti su takođe preuzeli državne medije koje su koristili za emitovanje svojih proglasa i prerano proglašene pobede. Takođe, turski mediji su i pre ponoći objavljivali vesti, u kojima se Erdogan proglašava "izdajnikom". ${ }^{18}$

Ubrzo pošto su pučisti shvatili da standardni pristup nije dovoljan, pobunjeni oficiri su pokušali da zauzmu i kanale privatnih televizija, pa čak i da ugase turski ogranak CNN-a. Cilj pučista je bio više nego očigledan, jer su želeli totalni medijski mrak prema sopstvenom narodu, odnosno smatrali su da će zauzimanjem svih medija imati potpunu kontrolu nad informacijama, kao i dovoljno prostora da ubede stanovništvo da im se pridruži.

Međutim, jednu ključnu činjenicu pučisti nisu uzeli u obzir, a to je sposobnost društvenih mreža i mobilne tehnologije. Njihov pokušaj kontrole medija rezultovao je potiskivanjem pučističkih vesti od strane domaćih i međunarodnih medija sa mnogo većim dometom. Time je prednost koju je vojska imala kroz inicijalni element iznenađenja ubrzo nestala. Ovakvo neznanje pučisti su skupo platili, a pogotovo je paradoksalna činjenica da pritvorenom turskom predsedniku nisu oduzeli mobilni telefon. Tačnije, par sati nakon početka vojnog udara, Erdogan je iskoristio svoj telefon, tačnije iPhonov FaceTime, kako bi preko Skajpa komunicirao sa svojom nacijom, pozivajući Turke da izađu na ulice i suprotstave se pobunjenicima. Njegova poruka se našla na svim društvenim mrežama, praćena slikama građana koji stoje ispred tenkova.

Od tada društvene mreže igraju ključnu ulogu i masovno prenose međunarodnu i domaću podršku predsedniku Redžepu Taipu Erdoganu. Gotovo većina stranih lidera, uključujući američkog predsednika, podržali su demokratski izabranog turskog predsednika. "Digitalno" uključivanje međunarodne i turske javnosti na društvenim mrežama nije samo pojačalo radoznalost turskih građana, već ih je i suočilo sa mogućom političkom realnošću koja bi nastala da je grupa zavereničkih oficira odnela pobedu. Protok informacija je ohrabrio, osnažio i mobilisao Turke da se suoče sa pobunjenicima i njihovim tenkovima.

\footnotetext{
${ }^{18}$ www.pinconsulting.co.rs/blog/neuspeli-vojni-puc-u-turskoj-drustvene-mreze, 10.06.2018.
} 
Značajan broj Turaka zajednički se upustio u strategiju od koje su pučisti najviše strahovali, zajedno su pravili gužve na putevima i mostovima, blokirajući oklopna vozila i komplikujući realizaciju operativnih planova. Ove slike su bile masovno šerovane u kobnoj noći na svim društvenim mrežama i davale su jasan signal da pobunjenici nisu pobedili i da su im šanse za pobedu sve manje. Predosećajući poraz, na hiljade pobunjenih vojnika se predalo. Slike koje je gledao ceo svet samo pokazuju da građani i te kako imaju važnu ulogu pri određivanju sopstvene političke sudbine, naročito kada se radi oko toga, ko nad njima vlada i na koji način.

Pomažući da se vojni udar u Turskoj osujeti, društvene mreže su „osnažile demokratiju“, čime se napokon videla i njihova pozitivna uloga u sukobima, budući da se u poslednjih nekoliko godina one optužuju kao glavni izvori za podstrekivanje mržnje i raspirivanje radikalizma, i to najviše od strane tzv. Islamske države, koja je, za razliku od turskih pučista, i te kako uvidela potencijale društvenih mreža.

\section{Zaključak}

Analizirajući sukobe u prošlom i ovom veku uz brojne specifičnosti i uzimajući u obzir razvoj, mesto i ulogu društvenih mreža u hibridnom ratovanju, za sada se ne može pouzdano predvideti dalji razvoj ovog fenomena. Trenutno, potpuno efikasan odgovor države na hibridne pretnje ne postoji, ali udruživanjem napora svih njenih subjekata bezbednosti, počevši od građana kao pojedinaca, pa do svih elemenata vlasti, mogu se predvideti i ublažiti posledice hibridnog sukoba. Svakako, građanin kao pojedinac pored vojnih, razvijaće i civilne sposobnosti, jer neće biti samo u situaciji da u ulozi vojnika dejstvuje vatrom na frontu, već i da iz svoje sobe (kancelarije, kabine) emituje mnogobrojne (dez)informacije u interesu svog naroda. Elementi sistema odbrane treba da preispitaju postojeće paradigme o društvenim mrežama i osmisle način delovanja u sajber prostoru, radi suzbijanja hibridnih pretnji i uspešnog suprotstavljanja u eventualnom hibridnom sukobu.

Dalje istraživanje ovog problema, treba usmeravati na mogućnost upotrebe društvenih mreža u zaštiti nacionalnih vrednosti i interesa, a prevashodno sa aspekta razmatranja uticaja savremenih hibridnih pretnji na razvoj sistema odbrane Republike Srbije.

\section{Literatura}

[1] Andrej Koribko, Transformacija hibridnog rata: Tehnologije protiv „obojenih revolucija“, www.srbin.info, 01.06.2016.

[2] Bojan Ž. Kuzmanović, Miroslav R. Terzić, Dejan R. Inđić, Moderno pobunjeništvo Islamska država, Vojno delo br. 2, Medija centar „Odbrana“, Beograd, 2016. str. 277 - 289.

[3] Globalna strategija EU o spoljnoj i bezbednosnoj politici - Zajednička vizija, zajedničko delovanje - jača Evropa, Savet EU, Brisel, 28.06.2016.

[4] European Commission, Joint Framework on countering hybrid threats, Brussels, 6.4.2016.

[5] Ivana Bulut, Uticaj društvenih mreža na poslovanje kompanija - doktorska disertacija, Megatrend univerzitet, Beograd, 2014.

[6] Jagello 2000, „Hybrid Warfare: A New Phenomenon in Europe's Security Environment”, Research paper by Jagello 2000 for NATO Information Centre in Prague in cooperation with Faculty of Social Studies, Masaryk University, Brno, and European Commision Representation in the Czech Republic, Praha-Ostrava 2015. 
[7] Luka Todorović, Milovan Milutinović, Globalne tendencije i hibridni rat, SVAROG, 2016. str. 19.

[8] Terzić, M., Talijan, M., Dumić, A., Stevanović, D., Hibridno ratovanje i globalne tendencije Evropske unije, 12. Međunarodno savetovanje Rizik i bezbednosni inženjering, Kopaonik, 2017. str. 47 - 53.

[9] Tomas S. Kun, Struktura naučnih revolucija, Nolit, Beograd, 1974, str. 59.

[10] FM 3-0 Operations, Headquarters Department of the Army, Washington, DC, 27 February 2008.

[11] Hoffman, Frank, „Conflicts in the 21st Century: The Rise of Hybrid Wars”, Potomac Institute for Policy Studies, Arlington, Virginia (December 2007).

[12] Hoffman, Frank, „Hybrid Threats: Reconceptualizing the Evolving Character of Modern Conflict", Strategic Forum, Institute of National Strategic Studies, NDU, No.240, 1-8, (April 2009).

[13] www.ec.europa.eu/epale/hr/blog/koliko-smo-digitalni-statistika-upotrebe-digitalnihtehnologija-u-srnoj-gori-i-u-regionu-u-2017, 10.06.2018.

[14] www.internet-srbija.com, 05.06.2018.

[15] www.pinconsulting.co.rs/blog/neuspeli-vojni-puc-u-turskoj-drustvene-mreze, 10.06.2018.

[16] www.sr.wikipedija.org/sr/Linkedln, 17.06.2018.

[17] http://www.politika.rs, 28.05.2017.

[18] www.xxzmagazin.com/evolucija-drustvnenog-povezivanja, 17.06.2018.

[19] www.sr.wikipedija.org/sr/Društvena_mreža, 17.06.2018.

[20] https://sr.wikipedia.org/wiki/Mark_Zuckerberg 